\title{
OPTIMASI PENEMPATAN TRANSPORTASI VERTIKAL PADA BANGUNAN RUMAH SAKIT (Studi Kasus: Rumah Sakit Bhakti Asih Brebes)
}

\author{
Sri Hartuti Wahyuningrum ${ }^{1}$ ) Hermin Werdiningsih ${ }^{1}$ ) Mustika K Wardhani ${ }^{2}$ ) \\ *) Corresponding author email : kweemustika@gmail.com
}

1)Departemen Arsitektur, Fakultas Teknik, Universitas Diponegoro, Semarang - Indonesia

2) Program Studi Arsitektur, Fakultas Teknik, Universitas Atma Jaya, Yogyakarta-Indonesia

\begin{tabular}{l}
\hline Article info \\
MODUL vol 19 no 1, issues period 2019 \\
\hline Doi $\quad: 10.14710 /$ mdl.19.1.2019.55-61 \\
Received $:$ 22nd may 2019 \\
Revised $:$ 23rd may 2019 \\
Accepted $:$ 23rd may 2019
\end{tabular}

Abstrak

Perancangan arsitektur pada bangunan publik khususnya pada bangunan dengan fungsi spesifik seperti Rumah Sakit harus mempertimbangkan faktor perencanaan fungsional yang terpadu dalam penyelesaian desainnya. Mengingat Bangunan Rumah Sakit mempunyai persyaratan bangunan yang relatif kompleks karena spesifikasi ruang pelayanan kesehatan yang disediakan. Terlebih bila bangunan tersebut merupakan bangunan bertingkat, sehingga faktor pengelolaan sirkulasi tidak hanya merupakan sirkulasi horisontal namun juga sirkulasi vertikal. Sirkulasi vertikal pada perancangan Bangunan Rumah Sakit selain berdasar pada kebutuhan aksesibilitas pada fungsi-fungsi ruang juga mempunyai pertimbangan dengan pembedaan alur bagi pasien, dokter dan perawat atau petugas serta pengunjung. Selain itu juga terkait upaya evakuasi sebagaimana persyaratan pada bangunan publik, namun ada kekhususannya karena fungsi dan karakteristik pemakai. Dalam konstruksi bangunan fasilitas transportasi vertikal merupakan salah satu komponen yang termasuk memerlukan alokasi dana yang cukup besar untuk itu pertimbangan efektifitas pemilihan jenis serta penempatannya menjadi pertimbangan utama. Metoda yang digunakan pada penelitian adalah metoda deskriptif yang akan menyimpulkan Hasil penelitian dapat digunakan sebagai panduan dalam proses perancangan arsitektur untuk perancangan Bangunan Rumah Sakit khususnya terkait optimasi penempatan transportasi vertikalnya.

Keywords: Bangunan Fungsi Spesifik; Transportasi Vertikal; Optimasi Penempatan

\begin{abstract}
PENDAHULUAN
Pembangunan bangunan gedung bertingkat pada masa sekarang semakin meningkat karena keterbatasan lahan sehingga membutuhkan pertimbangan efisiensi penggunaan lahan sehingga dapat mengakomodasi fungsi bangunan dengan fasilitas yang sesuai kebutuhan (Fischer \& Mausser, 2009). Sebagai jaminan untuk keselamatan terhadap penggunaan bangunan bertingkat maka diperlukan proses perancangan yang tepat serta memenuhi kaidah teknis yang berlaku, terlebih untuk bangunan dengan fungsi publik seperti bangunan Rumah Sakit (Nick-Weller, 2009).

Pelayanan kesehatan mempunyai persyaratan teknis spesifik untuk dapat beropersional dengan baik dimana hal-hal terkait kecepatan, kemudahan aksesibilitas pelayanan dengan keragaman pengguna bangunan termasuk yang berkebutuhan khusus menjadi pertimbangan penting, terlebih lagi terhadap keselamatan pemakai bangunan secara menyeluruh. Aspek pengelolaan dan penyelesaian transportasi vertikal menjadi sangat penting dengan beberapa pertimbangan baik unsur teknis, efektifitasnya maupun aspek biaya pembangunan menjadi dasar pertimbangan, selain unsur utama yaitu terakomodasinya sirkulasi pelayanan kesehatan yang sesuai. Penelitian ini dapat menjadi informasi bagi arsitek/professional di bidang perancangan khususnya untuk memahami konsep penempatan transportasi vertikal dan pemilihan jenisnya pada perancangan bangunan rumah sakit.
\end{abstract}

\section{LITERATUR STUDI}

1. Keandalan Bangunan, dapat dimaknai sebagai kondisi atau kemampuan yang dapat dipercaya, khususnya pada bangunan adalah kemampuan bangunan dalam memenuhi kriteria terhadap jaminan keselamatan, kesehatan, kenyamanan dan kemudahan bagi pengguna bangunan (PermenPU tahun 1998). Adapun yang dimaksud dalam penjelasan Bagian Keempat pada Undang- 
undang (UU) No. 28 Tahun 2002: persyaratan keandalan bangunan gedung sebagaimana dimaksud dalam Pasal 7 ayat (3), meliputi persyaratan keselamatan, kesehatan, kenyamanan dan kemudahan. Dan persyaratan kenadalan bangunan gedung sebagaimana yang dimaksud dalam ayat (1) ditetapkan berdasarkan fungsi bangunan gedung.

Persyaratan Keselamatan, terdiri dari persyaratan struktur bangunan gedung, persyaratan kemampuan bangunan gedung terhadap bahaya kebakaran, bahaya petir dan bahaya kelistrikan (K.Seiffler,2010 dan Leusseu, 1992).

Persyaratan Kesehatan, persyaratan sistem penghawaan, sistem pencahayaan, sanitasi \& penggunaan bahan bangunan gedung.

Persyaratan Kenyamanan, persyaratan kenyamanan ruang gerak dalam bangunan gedung, kondisi udara dalam ruang, pandangan, tingkat getaran dan kebisingan.

Persyaratan Kemudahan, Hubungan dari dan di dalam bangunan serta kelengkapan prasarana dan sarana.

2. Aksesibilitas, asas aksebilitas yang terdiri dari kemudahan, kegunaan, keselamatan, dan kemandirian (Goldsmith, 2000). Persyaratan teknis Aksesibilitas meliputi: Ukuran dasar ruang, Jalur Pedestrian, Jalur Pemandu, Area Parkir, Pintu, Ramp, Tangga, Lift, Kamar Kecil, Pancuran, Wastafel, Telepon, Peralatan control, Perabot, Rambu (PermenPU no30 tahun 2006).

3. Persyaratan Prasarana Transportasi dalam Rumah Sakit yang terdiri dari sistem hubungan horizontal dalam rumah sakit, Sistem Hubungan Vertikal dalam Rumah Sakit.

\section{MATERIAL DAN METODE}

Adapun Material yang digunakan untuk penelitian ini adalah sebagai berikut:

- Tahap Observasi bertujuan untuk mengidentifikasi konsep perencanaan dan konteks penempatan transportasi vertical

- Tahap Dokumentasi sebagai bentuk pendeskripsian terhadap studi kasus yang dipilih dan konsekuensi penempatannya.

- Tahap Kajian penempatan transportasi vertikal pada RS Bhakti Asih Brebes yaitu analisis dengan metode saintifik berkenaan. dengan konfigurasi tata ruang dan persyaratan teknisnya dalam menunjang pelayanan medik khususnya fungsi kinerja ruang (sirkulasi).

Sedangkan metode yang digunakan pada penelitian kali ini adalah metode deskriptif dengan studi kasus
Bangunan RS Bhakti Asih Brebes yang memfokuskan pada efisiensi transportasi.

\section{ANALISIS}

Studi kasus ditentukan berdasar pertimbangan bahwa dalam perencanaan Rumah Sakit Umum milik Swasta pertimbangan efisiensi dalam kaitannya untuk penghematan biaya pembangunan menjadi dasar untuk acuan dalam pembahasan tahap perencanaan. Mengingat investasi yang dilakukan merupakan pertimbangan utama ,selain adanya kewajiban pemenuhan standar teknis dan persyaratan pelayanan rumah sakit secara umum (Standar Akreditasi Rumah Sakit, 2011).

Sebagai Rumah Sakit Umum milik Swasta RS Bhakti Asih di Jatibarang Brebes merupakan salah satu contoh studi kasus yang tepat.

\section{Rencana Blok Plan}

Konsep tata massa bangunan menggunakan pola massa komposit sehingga hubungan antar bagian tidak terlalu jauh agar dapat memberikan pelayanan yang cepat, efisien, dan terarah (Truelove, 2000). Kesan kedekatan dengan lingkungan sekitar diharapkan dapat menciptakan suasana bebas, terbuka, tenang sehingga pasien tidak merasa jenuh. Kemungkinan penghawaaan dan pencahayaan menjadi baik. Faktor keamanan pasian dapat diatasi bila terjadi bencana (lihat figur 1).

Bentuk massa bangunan terdiri atas tiga massa utama dengan ketinggian antara 3-4 lantai berbentuk persegi panjang untuk memaksimalkan efisiensi ruang dan grid struktur yang akan diterapkan.

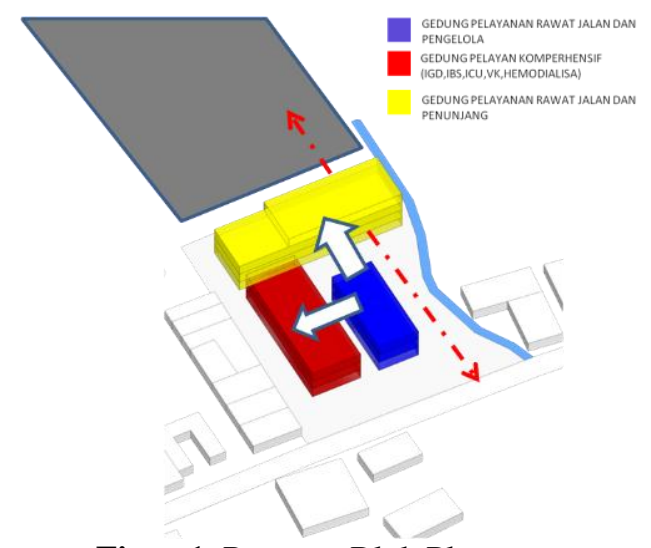

Figur 1. Rencana Blok Plan

Bangunan depan memiliki jumlah lantai sebanyak tiga tingkat, sementara bangunan belakang sebagian lantainya dibuka seolah bangunan diangkat dari lantai sehingga menciptakan akses penghubung untuk pengembangan area belakang. 


\section{Rencana Aksesibilitas dan Sirkulasi}

Aksesibilitas pada RS Bhakti Asih Jatibarang direncanakan terbagi atas tiga bagian: main entrance yang difungsikan sebagai akses rawat jalan, UGD entrance untuk pasien gawat darurat dan ambulans serta service entrance sebagai lalu lintas kendaraan servis dan unit jenazah.

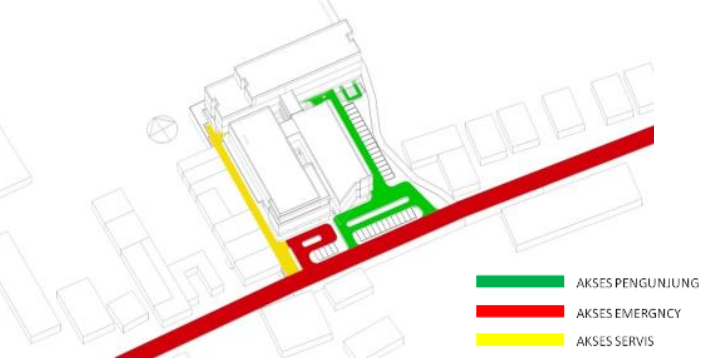

Figur 2. Rencana Blok Plan

Pembagian sistem sirkulasi dibagi menurut jenis kegiatannya yaitu sirkulasi pasien yang terdiri dari sirkulasi pasien rawat jalan - Sirkulasi pasien rawat inap - Sirkulasi pasien gawat darurat sebagai sistem yang dibentuk untuk mempermudah pertolongan (Runciman et al, 2009). Sirkulasi staf dan tim medis berperan dalam pertolongan utama pada pasien, pemisahan anatara sirkulasi staf dan tim medis serta pasien untuk mempermudah pertolongan (VA Design Guide, 2008). Sirkulasi pengunjung mendapatkan peranan penunjang dan terdapat batasan yang jelas dalam menentukan alur sirkulasi pasien. Sirkulasi Barang disebut supply system yang diartikan bahwa rumah sakit melayani poliklinik juga dan berhubungan dengan instalasi gawat darurat sehingga penempatan bersebelahan demi tujuan kemudahan (lihat figur 2).

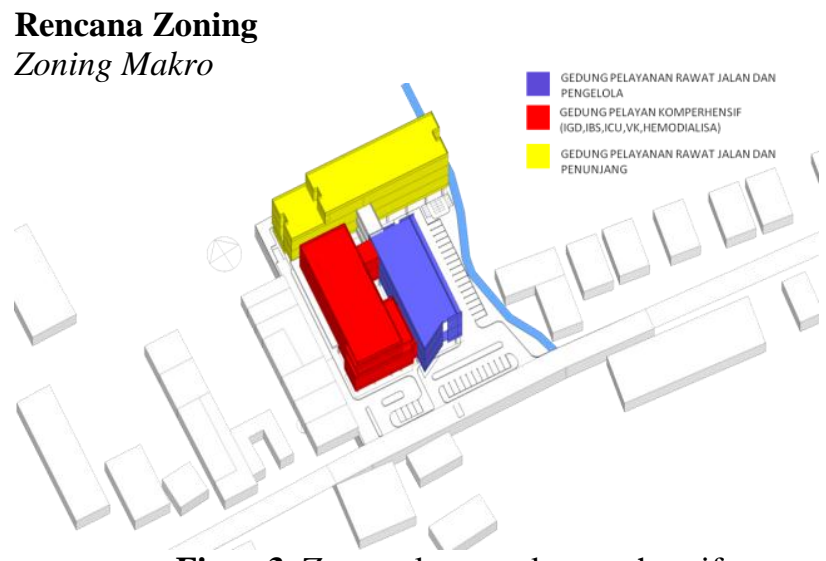

Figur 3. Zona pelayanan komprehensif

Pada rencana rumah sakit Bhakti Asih Jatibarang terbagi atas tiga zona besar, yaitu zona pelayanan awat jalan dan pengelola, zona pelayanan komprehensif (IGD, IBS, ICU, VK, HEMODIALISA) dan zona pelayanan rawat jalan dan penunjang bertujuan untuk mempermudah sirkulasi dan pelayanan agar tidak bercampu dan menyederhanakan sistem utilitas bangunan (lihat figur $3)$.

\section{Zoning Mikro}

Lantai 1

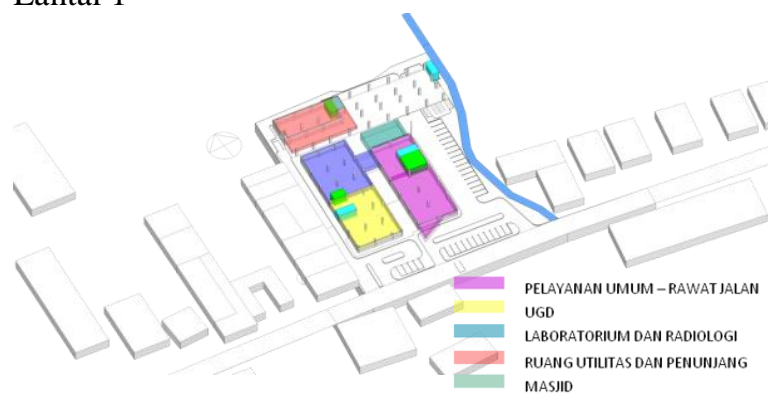

Figur 4. Zona pada lantai 1

Pada lantai satu terbagi atas zona rawat jalan (poliklinik), Zona UGD, Zona Laboratorium, Zona penunjang. Perletakan poliklinik (rawat jalan) pada lantai satu meningat pertimbangan kemudahah aksesibilitas pengunjung serta intensitas kegiatan yang cukup tinggi. Area penunjang diletakkan pada area belakang dibawah gedung rawat inap, tujuannya agar memisahkan sirkulasi dari sirkulasi utama dan servis (lihat figur 4).

Lantai 2

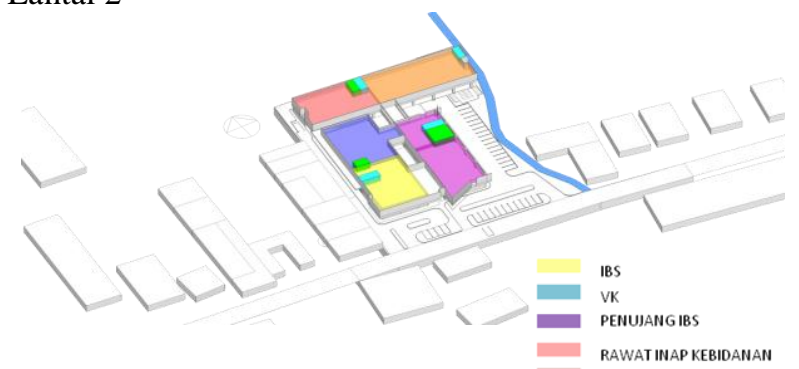

Figur 5. Zona IBS pada lantaie2 2 Vatimap anak

Pada lantai dua terbagi atas zona IBS (Instalasi bedah Sentral), ruang VK dan ruang rawat inap untuk anak dan kebidanan, peletakan zona ini bertujuan mendekatkan pencapaian dari ruang VK (lihat figur 5)

Lantai 3

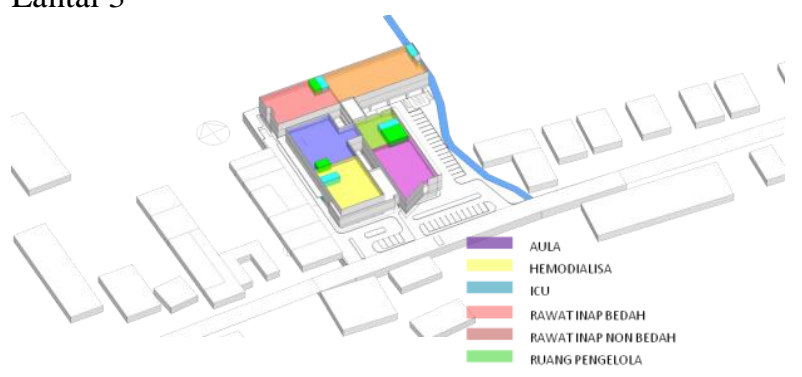

Figur 6. Zona IBS pada lantai 2 
Pada lantai tiga area zona gedung A diletakkan ruang pengelola dan aula bersama untuk memenuhi kebutuhan ruang bentang lebar (lihat figur 6). Pada gedung B terbagi atas zona ruang ICU dan Hemodialisa. Serta pada gedung C(IRNA) terbagi atas irna untuk bedah (infeksi) atau irna non bedah (penyakit dalam)

\section{Lantai 4}

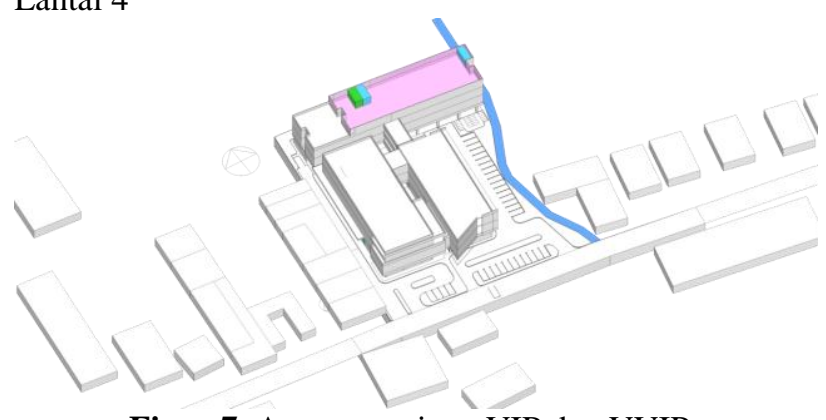

Figur 7. Area rawat inap VIP dan VVIP

\section{Gambar Rancangan}

a. Site Plan

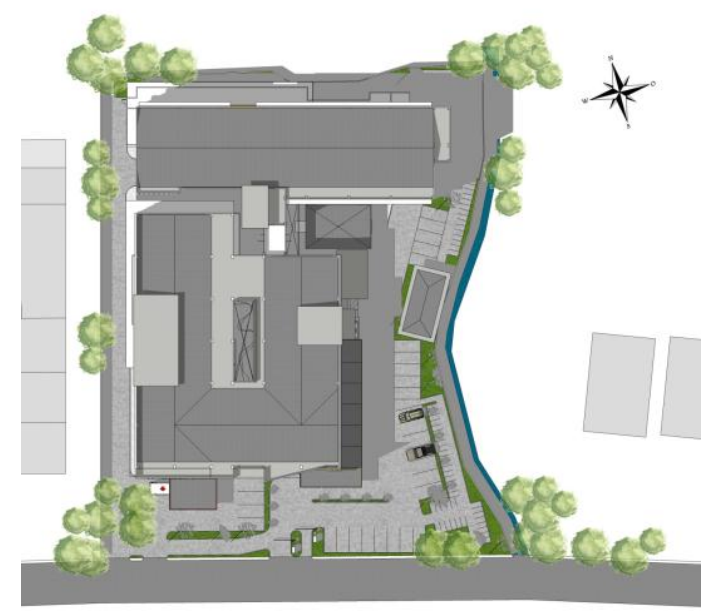

Figur 7. Site plan RS Bhakti Asih Brebes

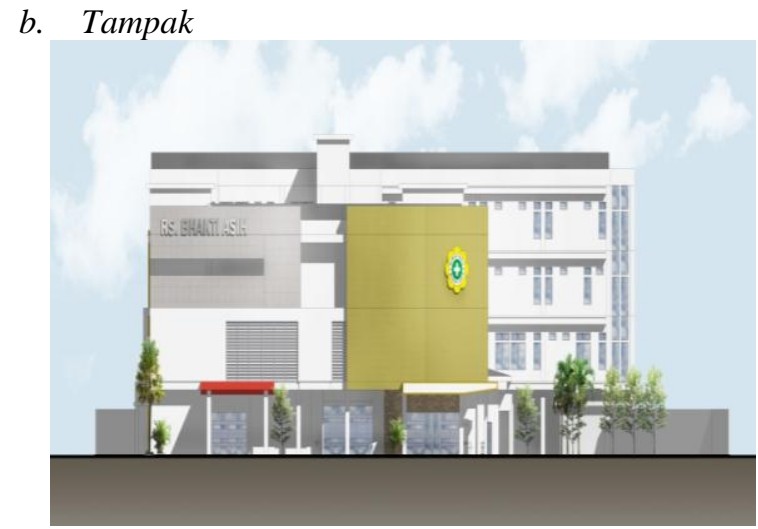

Figur 8. Site plan RS Bhakti Asih Brebes

\section{c. Perspektif}

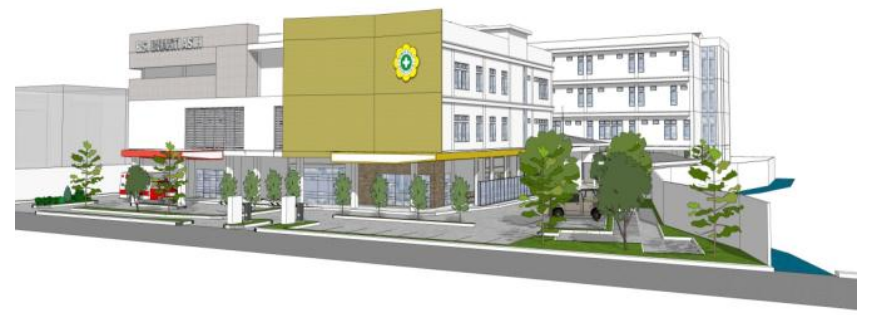

Figur 9. Perspektif RS Bhakti Asih Brebes

Analisis, menggunakan metoda saintifik, berkenaan dengan konfigurasi tata ruang dan persyaratan teknisnya dalam menunjang pelayanan medik khusus terutama terkait prosedur pelayanan kepada pasien khususnya terkait sirkulasi vertikal pada obyek studi kasus yang merupakan rumah sakit dengan bangunan bertingkat lantai 3 dan lantai 4 (lihat figur 7)

Pada tahap ini eksplorasi desain terhadap prosedur sirkulasi pada rumah sakit untuk menemukenali karakteristiknya yang nantinya akan dicari untuk penempatan transportasi vertical yang optimal sesuai lingkup pelayanan rumah sakit.

Tabel 1. Kajian Jenis Transportasi Vertikal Pada Rumah

\begin{tabular}{|c|c|c|}
\hline $\begin{array}{c}\text { Jenis } \\
\text { Transportasi } \\
\text { Vertikal }\end{array}$ & $\frac{\text { Sakit }}{\text { Fungsi }}$ & $\begin{array}{l}\text { Aksesibili } \\
\text { tas }\end{array}$ \\
\hline Tangga & $\begin{array}{c}\text { akses manusia \& } \\
\text { barang berkebatasan } \\
\text { manual, dengan } \\
\text { hambatan trap tangga }\end{array}$ & Vertikal \\
\hline Eskalator & $\begin{array}{l}\text { akses manusia \& } \\
\text { barang berkebatasan, } \\
\text { manual, dengan } \\
\text { hambatan trap tangga }\end{array}$ & Vertikal \\
\hline Ramp & $\begin{array}{c}\text { akses barang } \\
\text { (beroda), manusia } \\
\text { dan lainnya }\end{array}$ & Vertikal \\
\hline Lift & $\begin{array}{c}\text { Transportasi Vertikal } \\
\text { untukManusia } \\
\text { (Reguler) }\end{array}$ & Vertikal \\
\hline Dumb Waiter & $\begin{array}{c}\text { Transportasi Barang } \\
\text { skala sedang (s/d } 100 \\
\text { kgs) }\end{array}$ & Vertikal \\
\hline Pneumatic Tube & $\begin{array}{c}\text { Transportasi barang } \\
\text { skala kecil }\end{array}$ & Khusus \\
\hline $\begin{array}{l}\text { Conveyor } \\
\text { (Travelator) }\end{array}$ & $\begin{array}{l}\text { Transportasi barang } \\
\text { dan orang }\end{array}$ & Vertikal \\
\hline
\end{tabular}

Tiap lantai terdapat ruang dengan karakter pelayanan medik dan penunjang medik sampai pada ruang umum 
dan servis, koneksi antar ruang untuk pola hubungan horizontal dengan koridor sedangkan untuk pola hubungan vertikal dengan eskalator dan lift, termasuk transport barang dan obat menggunakan lift service maupun jenis dumb waiter.

Dengan demikian karakter bangunan bertingkat tidak menghambat pelayanan kinerja satu atap (komprehensif) untuk pasien. Namun untuk kemudahan dan pelayanan yang terintegrasi tetapi tetap efisien maka penempatan titik transportasi vertikal menjadi penting.Harga prasarana sangat mempengaruhi dalam saat pelaksanaan pembangunan dan juga untuk saat maintenance, khususnya untuk perlengkapan yang sifatnya mekanik. Selain itu kelengkapan prasarana juga memerlukan penyediaan ruang khusus dan penempatan mesinmesinnya.

\section{Optimasi Penempatan Transportasi Vertikal pada Studi Kasus}

Untuk menentukan kajian terhadap penempatan transportasi vertical pada bangunan rumah sakit tentunya selain mengenali karakter jenis transportasinya juga harus memperhatikan karakter blok massa bangunan dan jenis pelayanan (atau kelompok fungsinya), integrasi diantaranya serta ukuran dari blok massa terkait jarak pelayanan (IAEA HUMAN HEALTH REPORTS No. 10; Mcmorrough,, 2006; Mausser, 2006).

Untuk obyek studi kasus RS Bhakti Asih - Jatibarang Brebes dapat digambarkan untuk penetapan penempatan titik transportasi vertical mengacu pada pertimbangan sebagai berikut :

\section{Kelompok massa bangunan \\ 2.KelompokFungsi pelayanan \\ 3.Ketinggian bangunan \\ 4.PelayananKhusus}

Total jumlah dan jenis transportasi vertical yang dipilih adalah Lift untuk Bed pasien dan dengan penempatan pada area yang mengakomodasi pelayanan pasien (baik untuk pelayanan medik/tindakan maupun untuk pelayanan medik/rawat inap) mengacu pada kelompok pelayanan serta jarak yang memadai untuk kegiatan pelayanan.

\section{Kajian Lay Out dan Blok Massa Bangunan Terhadap Kelompok Fungsi Ruang}

Block Plan :terdapat 3 (tiga) blok massa utama yang terdiri dari Gedung Pelayanan Rawat Jalan dan Pengelola, Gedung pelayanan Komprehensif (IGD, IBS,ICU,VK dan Hemodialisa) dan Gedung Pelayanan Rawat Inap serta Penunjang. Mengacu hasil blok plan massa bangunan dan kelompok fungsi ruang sebagaimana tersebut diatas maka ketiganya memerlukan koneksi yang terintegrasi (lihat figur 9).

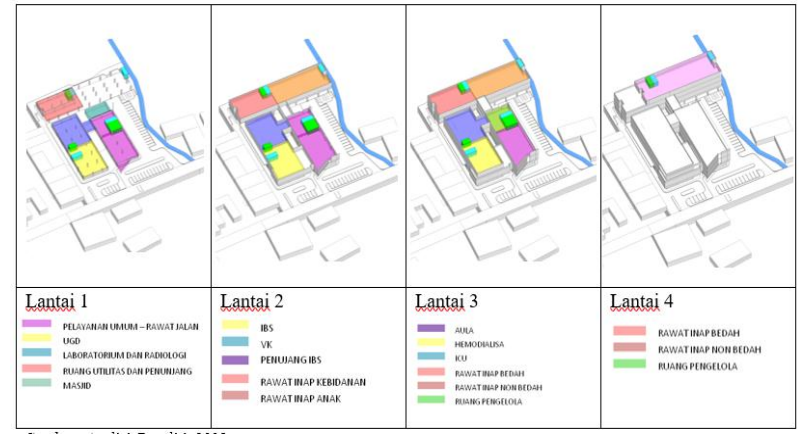

Figur 9. 3 kelompok blok massa bangunan

Secara prinsip terdapat 3 (tiga) kelompok blok massa bangunan yang dalam kelompok besarnya dapat dibedakan menjadi :

1.Blok 1 :Pelayanan Rawat Jalan dan Pengelola

2.Blok 2 :Pelayanan Medik Komprehensif

3.Blok 3 :Pelayanan Rawat Inap dan Penunjang

Ketiganya saling berkaitan dan mempunyai integrasi yang erat, karakter penempatan blok massa bangunan memberikan kemudahan dalam membentuk jalur koneksi maupun penempatan titik transportasi vertikalnya yaitu sebagai berikut :

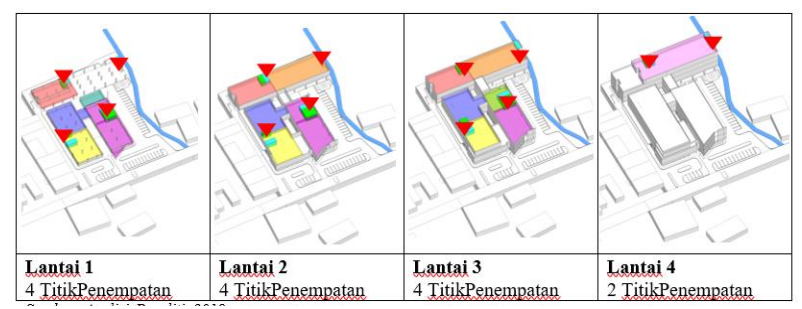

Figur 10. Titik plot penempatan Transportasi Vertikal Jenis Tangga

Dari masing-masing blok terdapat 1 (satu) sampai 2 (dua) titik transportasi vertical untuk tangga mengacu jarak atau bentang massa bangunan. Penerapan varian pada jarak $24 \mathrm{~m}$ dan $32 \mathrm{~m}$, mengingat penggunaan trave bangunan pada modul $8 \mathrm{~m}$ (setiap $3 \mathrm{~s} / \mathrm{d} 4$ modul) dapat dilihat di figur 10 dan mengacu sesuai jumlah lantai bangunan (varian 3 lantai dan 4 lantai). Sedangkan untuk transportasi vertical jenis lift (elevator) bed pasien penempatannya sebagai berikut (lihat figur 11) :

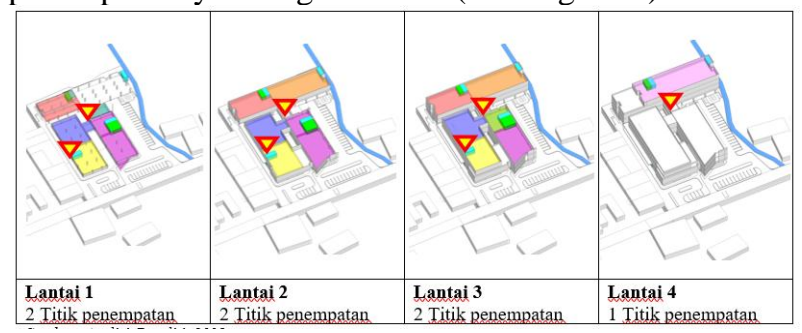

Figur 11. Titik plot penempatan Transportasi Vertikal Jenis Lift 
Untuk penempatan lift atau elevator pasien satu titik pada gedung medic komprehensif sama dengan penempatan tangga dan untuk yang gedung pelayanan rawat inap dan penunjang serta gedung rawat jalan dan pengelola ditempatkan pada posisi yang berbeda dengan titik plot tangga. hal ini menjadi pertimbangan untuk efisiensi jumlah lift/elevator yang dipasang.

\section{Koneksi dan Optimasi JarakPelayanan}

Dengan penempatan titik tangga dan titik lift (elevator) yang berbeda hal ini dilakukan untuk mengoptimalkan jumlah serta distribusi peran lift (elevator) khususnya untuk bed pasien pada titik yang strategis, yang mengacu pada pertimbangan :

- Jarak pelayanan masih memenuhi persyaratan jarak tempuh

- Mengakomodasi karakter fungsi tangga dan lift yang tidak sepenuhnya sama (terdapat fungsi tangga yang sifatnya untuk tangga emergensi dan tangga regular).

- Titik transportasi yang terbatas penggunaannya (tidak untuk umum)

- Efisiensi penempatan lift terkait investasi biaya pembangunan (batasan jumlah lift).

Mengacu keempat hal tersebut maka dalam konfigurasi plot pada desain RS Bhakti Asih diperoleh seperti pada figur 12 :

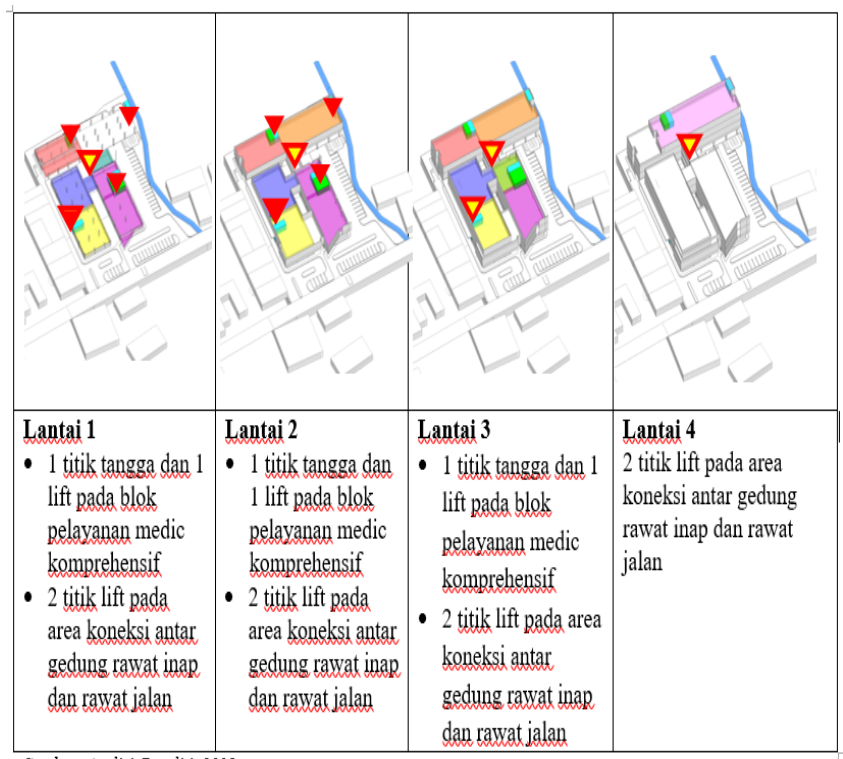

Figur 12. Konfigurasi plot desain RS Bhakti Asih

Konsep penempatan lift (elevator bed pasien ) pada titik yang berbeda dengan tangga (yang terletak antara gedung rawat jalan dan rawat inap) adalah untuk mendapatkan fungsi yang lebih optimal dari elevator ini yaitu selain untuk akses pasien ke rawat inap juga dapat berfungsi melayani public lainnya untuk kepentingan mengunjungi pasien maupun kegiatan pengelola yang terletak diatas pelayanan rawat jalan. Jarak tempuh pelayanan maksimal $32 \mathrm{~m}$. Dalam arti masih memenuhi untuk pelayan (covering area transportasi vertikal) berlaku untuk tangga dan lift.

Untuk area blok gedung pelayanan medic komprehensif peran lift dan tangga yang ada juga didedikasikan dengan pengamanan free smoked lobby sehingga area lobby hall nya dapat digunakan untuk evakuasi kegawatdaruratan.

Tabel 1. Simulasi Kajian

\begin{tabular}{ccc}
\hline Dasar Pertimbangan & $\begin{array}{c}\text { Ranking } \\
\text { Prioritas } \\
\text { Panking }\end{array}$ & $\begin{array}{c}\text { Prioritas } \\
\text { 2 }\end{array}$ \\
\hline Jarak pelayanan masih & $\sqrt{ }$ & \\
memenuhi persyaratan jarak & & $\sqrt{ }$ \\
Mengakomodasi karakter & & \\
fungsi tangga \& lift yang & & \\
tidak sepenuhnya sama & & \\
(terdapat fungsi tangga & & \\
yang sifatnya untuk tangga & & \\
emergensi \& tangga & & \\
regular). & & \\
Titik transportasi yang & $\sqrt{ }$ \\
terbatas penggunaannya \\
(tidak untuk umum) \\
Efisiensi penempatan lift \\
terkait investasi biaya \\
pembangunan (batasan \\
jumlah lift).
\end{tabular}

\section{HASIL DAN DISKUSI}

Kesimpulan disusun setelah hasil analisis yang berupa pemahaman dan kajian karakter blok massa bangunan, jenis pelayanan, karakter pelayanan dan ketinggian jumlah lantai bangunan serta ukuran bangunan, maka untuk optimasi penempatan transportasi vertical pada RS Bhakti Asih Jatibarang Brebes dapat dijabarkan sebagai berikut :

1. Pelayanan untuk pasien sesuai dengan karakter pasien (berjalan/ambulatory, berkursi roda dan dengan bed).

2. Persyaratan transportasi vertical pada rumah sakit harus mengakomodasi karakter penggunanya serta prosedur pelayanan yang menjadi standar pelayanan.

3. Jenis atau ragam prasarana transportasi vertical yang lazim tersedia pada rumah sakit :

- Elevator Pasien

- Elevator Barang 
- Eskalator untuk ruang public yang kontinyu

- Dumb Waiter

- Tangga (TanggaDarurat)

- Pneumatic Tube (obat, sampling dan data) koneksi dengan gedung lain yang terkait (seperti laboratorium)

4. Melihat kondisi lapangan dan desain konfigurasi blok massa bangunan RS Bhakti Asih Jatibarang maka pilihan jenis transportasi vertikalnya meliputi : Elevator Pasien, Tangga (Tangga Darurat) dan Dumb Waiter (untuk pelayanan dokumendan barang skala kecil)

5. Kompleksitas jenis ruang maupun persyaratan masing-masing ruang terutama ruang khusus menjadi perhatian bagi desainer/arsitek dalam konteks desain rumah sakit secara komprehensif.

\section{REKOMENDASI}

Untuk obyek studi kasus RS Bhakti Asih Jatibarang Brebes dapat digambarkan untuk penetapan penempatan titik transportasi vertical mengacu pada pertimbangan sebagai berikut :

a. Kelompok massa bangunan

b. Kelompok Fungsi pelayanan

c. Ketinggian bangunan (jumlah lantai bangunan sesuai blok massa bangunan)

d. Pelayanan Khusus

Total jumlah dan jenis transportasi vertikal yang dipilih adalah Lift untuk Bed pasien (dengan ukuran yang cukup leluasa untuk bed pasien, lift ini juga dapat mengangkut penumpang regular dan barang dengan kapasitas yang memadai cukup besar) dan dengan penempatan pada area yang mengakomodasi pelayanan pasien (baik untuk pelayanan medik/tindakan maupun untuk pelayanan medik/rawat inap).

\section{REFERENSI}

Fischer, Joachim \& Philipp Meuser (2009) 'Construction and Design Manual Accessible Architecture', DOM Publisher.

K. Shleifer, Simone (2010) 1000 Details in Architecture, booOs publishers bvba.

Laseau, Paul \& James Tice (1992) Frank Lloyd Wright - Between Principle and Form, Van Nostrand Reinhold NY

Nick-Weller, Christine \& Hans Nickl (2009) Hospital Architecture + Design, Braun Publishing AG

Runciman,William., Hibbert ,Peter., Thomson, Richard., Van Der Schaaf ,Tjerk., Sherman, Heather., Lewalle, Pierre (2009) Towards an International Classification for Patient Safety: key concepts and terms, International Journal for Quality in Health Care 2009; Volume 21, Number 1: pp. $18-26$
VA Design Guide - Nuclear Medicine (2008). Departement of Veterans Affair, Veterans Health Administration Office of Facilities Management , Radioteraphy Facilities : Master Planning and Concept Design Consideration, IAEA HUMAN HEALTH REPORTS No. 10, International Atomic Atomic Agency Vienna, (2014), the IAEA web site: http://www.iaea.org/Publications/index.html

Goldsmith, Selwyn. (2000) Universal Design, Architectural Press.

Mcmorrough, Julia. (2006) Materials Structures Standards, Rockport.

Mueser, Philipp (2006) New Hospital Buildings in Germany - Volume 1: General Hospitals and Health Centres, Dom-Publishers.

Truelove, James Grayson. (2000) This Way - Signage Design for Public Spaces, Rockport.

\section{Regulasi}

Keputusan Menteri Pekerjaan Umum Republik Indonesia Nomor : 468/KPTS/1998 Tanggal 1 Desember 1998 Tentang Persyaratan Teknis Aksesibilitas Pada Bangunan Umum dan Lingkungan

Standar Akreditasi Rumah Sakit (2011) Kementrian Kesehatan Republik Indonesia.

Undang-undang Republik Indonesia Nomor 28 Tahun 2002 tentang Bangunan Gedung

Peraturan Menteri Pekerjaan Umum Nomor 30/PRT/M/2006 Tanggal 1 Desember 2006 tentang Pedoman Persyaratan Teknis Bangunan Gedung 